\title{
Synergistic Effect of Adsorption and Enzymatic Conversion in the Bisphenol-A Removal by Laccase Immobilized on Poly(glycidyl methacrylate-co-ethyleneglycol dimethacrylate)
}

\author{
Claudinei F. Melo, ${ }^{*, a}$ Leandro A. Silva, ${ }^{b}$ Luciana C. Costa ${ }^{a, b}$ and Monica R. C. Marques ${ }^{a}$ \\ anstituto de Química, Universidade do Estado do Rio de Janeiro (UERJ), \\ 20550-900 Rio de Janeiro-RJ, Brazil \\ ${ }^{b}$ Laboratório de Síntese Orgânica, Centro Universitário Estadual da Zona Oeste (UEZO), \\ 23070-200 Rio de Janeiro-RJ, Brazil
}

\begin{abstract}
Carriers with different functional groups (epoxy, aldehyde, ethyldiazonium, phenyldiazonium and amino) were tested for immobilization of $T$. versicolor laccase on GMA-co-EGDMA (glycidyl methacrylate-co-ethyleneglycol dimethacrylate) microspheres. Laccase immobilized on GMA-co-EGDMA containing the phenyldiazonium functional group showed the highest activity (96.3 $\left.\mathrm{U} \mathrm{g}^{-1}\right)$. The immobilized laccase was used for removal of bisphenol-A (BPA) from aqueous solution. The temperature effect was significant on activity, but insignificant on BPA removal by the immobilized laccase. In the temperature range $10-60{ }^{\circ} \mathrm{C}$, the removal of BPA by laccase in the immobilized form was about four times higher than that in the free form. Swelling does not affect the activity of immobilized laccase, but after 8 cycles of 2,2' -azino-bis(3-ethylbenzothiazoline6-sulphonic acid) (ABTS) oxidation, non-swollen immobilized laccase was able to retain $71 \%$ of the starting activity while the $24 \mathrm{~h}$ swollen kept $61 \%$. At neutral $\mathrm{pH}$, adsorption onto the immobilized laccase accounted for $92 \%$ of the BPA removed while enzymatic conversion accounted for $8 \%$. However, when increasing the $\mathrm{pH}$ to 10 , the fraction of BPA removed by adsorption decreased to $67 \%$ and by enzymatic conversion increased to $33 \%$.
\end{abstract}

Keywords: immobilized laccase, adsorption, acrylic resin, phenyldiazonium group, covalent attachment, enzyme reuse

\section{Introduction}

Enzymes are efficient catalysts that are able to convert their substrates by specific catalytic steps at high reaction rates, giving environmentally benign byproducts and intermediates. ${ }^{1}$ However, the cost of enzyme production is prohibitive and the use of enzymes in free form, i.e., dissolved in the reaction medium, limits their reuse in subsequent reaction batches. As a result, the use of enzymes for processes in an industrial scale can be technically and economically unfeasible. ${ }^{2}$ Those limitations can be overcome by immobilization of the enzyme, improving its storage and operational stability and enabling its easy separation from the reaction medium and reuse. ${ }^{3}$

Several methods for enzyme immobilization are currently available. Those methods can be categorized into binding to a carrier, entrapment in a polymer network

*e-mail: claudinei_fmelo@hotmail.com and crosslinking of enzyme molecules. ${ }^{4}$ Immobilization by covalent attachment is particularly advantageous since the strong interaction prevents enzymes from leaching from the carrier under extreme operational condition. ${ }^{4}$ Moreover, enzyme immobilization increases the resistance to denaturing conditions, such as extreme $\mathrm{pH}$ and temperature, and decreases the inhibition caused by medium components, organic solvents or byproducts. ${ }^{5}$

The choice of the most suitable method for enzyme immobilization depends on the characteristics of the carrier and enzyme. The reactions between the functional groups of the polymeric carrier and the amino acid (AA) residues on enzyme surface determine the stability and activity of the immobilized biocatalyst. ${ }^{3}$ A number of functional groups have been used to provide anchoring between enzyme and polymeric carriers, such as epoxy, amino, diazonium and diol. ${ }^{6}$ Those groups react with amino, acid and phenolic groups, respectively, on the enzyme surface, forming covalent bonds. ${ }^{7,8}$ Carriers with functional groups that react 
preferentially with AA residues from the enzyme surface, and not with those from the catalytic site, should be the most suitable for enzyme immobilization. Considering that each enzyme has a unique AA sequence and a 3D structure, ${ }^{9}$ a tailored method is required to best immobilize the enzyme on a given carrier. ${ }^{7}$

An enzyme that can be particularly benefited by immobilization is laccase. It preferentially catalyzes the oxidation of phenols in presence of oxygen. Laccase can also act on non-phenolic compounds in the presence of redox mediators, expanding the range of compounds that can be oxidized..$^{10}$ Due to its low substrate-specificity, laccase has enormous potential for degradation of xenobiotics, design of biosensors and biofuel cells, phenol detection, and bleaching and delignification of cellulose, among others. ${ }^{5}$ However, industrial applications have been hampered by high cost, low stability and poor reusability of laccase in free form. ${ }^{11}$ Therefore, the use of immobilization techniques can improve operational properties of laccase, such as stability to $\mathrm{pH}$ and temperature changes, reusability and long-term stability. ${ }^{12}$

The aims of this study were to $(i)$ select a method suitable for immobilization of laccase from Trametes versicolor onto porous GMA-co-EGDMA (glycidyl methacrylateco-ethyleneglycol dimethacrylate) microspheres by covalent bonding and (ii) evaluate the contribution of the mechanisms of adsorption and enzymatic conversion on the removal of bisphenol-A (BPA) from aqueous solution. To the best of our knowledge, this is the first paper reporting that laccase immobilized on an acrylic resin removes BPA from aqueous media by adsorption and enzymatic conversion. Moreover, it was found that the $\mathrm{pH}$ of the reaction medium determines the predominant mechanism of BPA removal.

\section{Experimental}

Synthesis of porous poly(GMA-co-EGDMA) microspheres

GMA-co-EGDMA resin was synthesized by aqueous suspension polymerization in a $1 \mathrm{~L}$ three-necked round bottom reactor flask equipped with a mechanical stirrer and a reflux condenser. The organic phase was composed of GMA $\left(32.7 \mathrm{~cm}^{3}\right)$ and EGDMA $\left(11.3 \mathrm{~cm}^{3}\right)$, (2,2'-azobis(2-methylpropionitrile)) (AIBN) $(0.49 \mathrm{~g})$ and cyclohexane $\left(22 \mathrm{~cm}^{3}\right)$. The aqueous phase consisted of poly(vinyl alcohol) (PVA) (1.98 g), $\mathrm{NaCl}$ (3.96 g) and deionized water $\left(198 \mathrm{~cm}^{3}\right)$. The aqueous phase was transferred into the flask followed by the organic phase. The system was continuously stirred at $350 \mathrm{rpm}$ and $85^{\circ} \mathrm{C}$ for $24 \mathrm{~h}$. The beads obtained were washed several times with hot water $\left(70^{\circ} \mathrm{C}\right)$, ethanol and methanol, and finally dried at atmospheric pressure at $60{ }^{\circ} \mathrm{C}$, for $48 \mathrm{~h}$. Resin was sieved in a sieve analyzer (Bertel, Brazil) and the microspheres retained in the 60 mesh sieve, with particle diameter of 250-300 $\mu \mathrm{m}$, were further chemically modified and used for laccase immobilization.

\section{Synthesis of the polymeric carriers}

GMA-co-EGDMA microspheres were modified to produce the carriers for laccase immobilization. The carrier (i) GMA-EGDMA was the non-modified resin and the carriers (ii) resin modified by $p$-phenylenediamine in buffer and then diazoted (PDA-BUF-DIAZO), (iii) resin modified by $p$-phenylenediamine in dimethylformamide (PDA-DMF), (iv) resin modified by ethylenediamine in DMF and then diazoted (EDA-DMF-DIAZO), (v) resin

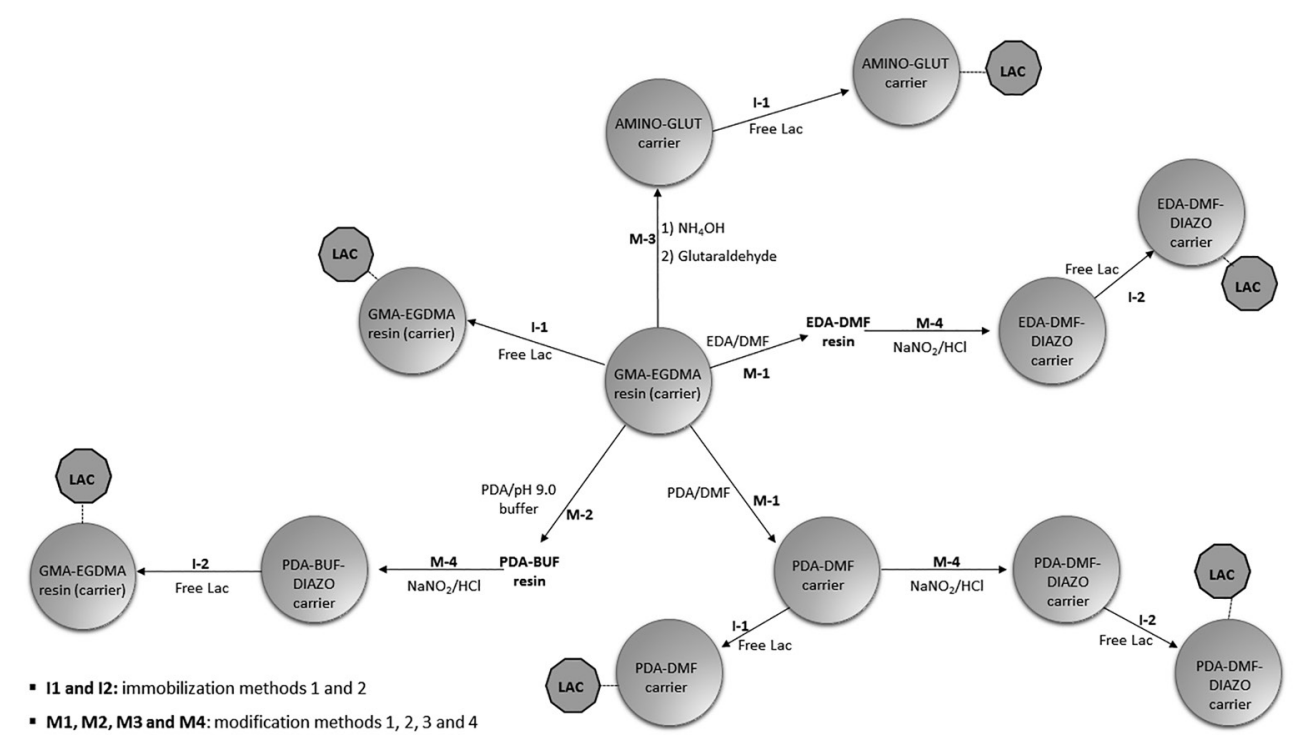

Figure 1. Simplified scheme showing the modification steps on the GMA-EGDMA resin to immobilize the enzyme laccase. 
modified by $p$-phenylenediamine in DMF and then diazoted (PDA-DMF-DIAZO), (vi) resin modified by $\mathrm{NH}_{4} \mathrm{OH}$ aqueous solution followed by glutaraldehyde activation (AMINO-GLUT) were synthesized by chemical modification of the copolymer, as illustrated in the Figure 1. The modification methods are described as the follows.

\section{Method M-1}

Copolymer $(1.00 \mathrm{~g})$, diamine $(0.96 \mathrm{~g}$ of EDA or $1.73 \mathrm{~g}$ of PDA) and DMF $\left(20 \mathrm{~cm}^{3}\right)$ were transferred to a three-necked round bottom reactor flask. The reaction medium was stirred continually at $80^{\circ} \mathrm{C}$ and $100 \mathrm{rpm}$, for $24 \mathrm{~h}$. Beads were filtered off, washed several times with methanol and acetone and then dried in an oven at $40{ }^{\circ} \mathrm{C}$, for $24 \mathrm{~h} \cdot{ }^{13}$ The modified resins were designated EDA-DMF and PDA-DMF, respectively.

\section{Method M-2}

Copolymer (1.00 g), PDA (1.73 g) and pH 9.0 carbonate buffer solution $\left(100 \mathrm{~cm}^{3}\right)$ were placed in an Erlenmeyer flask and then stirred for $90 \mathrm{~min}$ at $100 \mathrm{rpm}$ and $40{ }^{\circ} \mathrm{C}$. Microspheres were washed with deionized water and acetone and then dried at $40{ }^{\circ} \mathrm{C}$, for $24 \mathrm{~h} .{ }^{14}$ Modified resin was designated PDA-BUF.

\section{Method M-3}

GMA-co-EGDMA beads $(0.3 \mathrm{~g})$ and $28-30 \%(\mathrm{~m} / \mathrm{m})$ ammonium hydroxide $\left(20 \mathrm{~cm}^{3}\right)$ were added in a three-necked round bottom reactor flask and then slowly stirred at $50{ }^{\circ} \mathrm{C}$ for $24 \mathrm{~h}$. Microbeads were washed with deionized water until the washing water turned neutral and dried at $40{ }^{\circ} \mathrm{C}$ for $72 \mathrm{~h}$. Ammonia-modified resin was dispersed in phosphate buffered saline ( $\mathrm{pH}$ 8.0) containing 5\% v/v glutaraldehyde $\left(20 \mathrm{~cm}^{3}\right)$. After reaction, the microspheres were washed with deionized water and dried at $40{ }^{\circ} \mathrm{C}$ for $72 \mathrm{~h} .{ }^{15}$ The glutaraldehyde-activated and ammonia-modified resin was designated AMINO-GLUT.

\section{Method M-4}

Diazotization was carried out in a two-necked round bottom reaction flask immersed in an ice bath. PDA or EDA modified resin $(1.0 \mathrm{~g})$ was dispersed in a $0.8 \mathrm{~mol} \mathrm{~L}^{-1}$ sodium nitrite solution $\left(50 \mathrm{~cm}^{3}\right)$ and, under slow stirring, $50 \mathrm{~cm}^{3}$ of $4 \mathrm{~mol} \mathrm{~L}^{-1}$ hydrochloric acid was added dropwise. After $40 \mathrm{~min}$, the diazotized resin was washed with plentiful cold deionized water and citrate-phosphate buffer. ${ }^{14}$ The carriers obtained by diazotization of resins reacted with EDA or PDA in DMF (method M-1) were designated EDA-DMF-DIAZO and PDA-DMF-DIAZO; and that using resin reacted with PDA in carbonate buffer (method M-2) was designated PDA-BUF-DIAZO.

\section{Modified-resin characterization}

The GMA-EDGMA copolymers were characterized by determining: apparent density by the graduated cylinder method, ${ }^{16}$ surface area and pore volume distribution by nitrogen adsorption measurements following the BET (Brunauer-Emmet-Teller) and BJH (Barrett-JoynerHalenda) methods, respectively (Micromeritcs, ASAP 2010 apparatus). The high apparent density $\left(0.61 \mathrm{~g} \mathrm{~cm}^{-3}\right)$ combined with the low surface area $\left(6.5 \mathrm{~m}^{2} \mathrm{~g}^{-1}\right)$ and pore volume $\left(0.06 \mathrm{~cm}^{3} \mathrm{~g}^{-1}\right)$ suggest that the structure of the GMA-EDGMA resin has low porosity degree. ${ }^{16}$

Fourier transform infrared (FTIR) spectra were recorded on transmittance mode on a PerkinElmer FTIR spectrometer (USA). Samples were pelletized using $\mathrm{KBr}$ spectroscopy grade. The scanning range was from 500 to $4000 \mathrm{~cm}^{-1}$ at a resolution of $2 \mathrm{~cm}^{-1}$. Thirty-two scans were collected for each sample.

${ }^{13} \mathrm{C}$ nuclear magnetic resonance (NMR) spectra were obtained using Agilent spectrometer, Tecmag console upgraded (Texas, USA), operating at $8 \mathrm{kHz}$. Copolymer samples were packed in a $7 \mathrm{~mm}$ zirconia rotor with Kel-F end-caps and spun at $4 \mathrm{kHz}$ in a Bruker HP WB 73A DB MAS probe. ${ }^{13} \mathrm{C}$ spectra were acquired using a $10 \mu \mathrm{s}\left(90^{\circ}\right)$ pulse with ${ }^{1} \mathrm{H}$ decoupling in the inversegated mode accompanied with recycle delay of $30 \mathrm{~s}$ to fulfill optimum quantitative condition. Chemical shifts $\delta\left({ }^{13} \mathrm{C}\right)$ were externally referenced to the glycine carbonyl signal (176.4 ppm).

\section{Laccase immobilization}

Two methods were used for the immobilization of laccase on the carriers. Immobilization method I-1 was used for the carriers GMA-EGDMA, PDA-DMF and AMINO-GLUT; while the method I-2 for the carriers EDA-DMF-DIAZO, PDA-DMF-DIAZO and PDA-BUF-DIAZO (Figure 1).

\section{Immobilization method I-1}

Carrier $(1 \mathrm{~g})$, laccase $(0.025 \mathrm{~g})$ and $\mathrm{pH}$ 6.8 PBS buffer $\left(20 \mathrm{~cm}^{3}\right)$ were transferred to an Erlenmeyer flask. After $24 \mathrm{~h}$ incubation in an orbital shaker at $30^{\circ} \mathrm{C}$ and $100 \mathrm{rpm}$, particles were filtered and washed with $\mathrm{pH} 5.0$ citratephosphate buffer $\left(0.1-0.2 \mathrm{~mol} \mathrm{~L}^{-1}\right){ }^{17}$

\section{Immobilization method I-2}

Carrier was incubated with laccase in $\mathrm{pH} 5.0$ citratephosphate buffer $\left(80 \mathrm{~cm}^{3}\right)$ under mild stirring at $5{ }^{\circ} \mathrm{C}$ for $16 \mathrm{~h}^{14}$

The amount of immobilized enzyme was calculated by subtracting the activity of free laccase ${ }^{18}$ that remained in 
the supernatant solution at the end of the incubation from the starting activity. ${ }^{2}$

\section{Determination of activity of immobilized laccase}

The method used for the determination of free laccase ${ }^{18}$ was adapted to determine the activity of immobilized laccase. Lyophilized immobilized enzyme and $3.6 \mathrm{~cm}^{3}$ of pH 5.0 buffer solution were transferred to a $10 \mathrm{~cm}^{3}$ screw-capped vial (Hach, USA). After adding $0.4 \mathrm{~cm}^{3}$ of $20 \mathrm{mmol} \mathrm{L}^{-1}$ ABTS (2,2'-azino-bis(3-ethylbenzothiazoline6-sulphonic acid)), the vial was vigorously stirred by a vortex to keep the immobilized laccase suspended. The reaction was monitored by measurement of the $420 \mathrm{~nm}$ absorbance (Hach DR 5000, USA) every $20 \mathrm{~s}$, during $240 \mathrm{~s}$. Activity was calculated by equation 1 .

Activity of immobilized enzyme $(\mathrm{U} / \mathrm{g})=10^{6} \frac{\Delta \mathrm{A}}{\Delta \mathrm{t}} \frac{\mathrm{V}}{\varepsilon \mathrm{Lm}}$

where $\frac{\Delta \mathrm{A}}{\Delta \mathrm{t}}$ is the increase rate of the $420 \mathrm{~nm}$ absorbance in $\min ^{-1}, \mathrm{~V}$ is the volume of the reaction medium in $\mathrm{L}, \varepsilon$ is the molar absorptivity of the radical cation form of ABTS (3600 $\mathrm{mol}^{-1} \mathrm{~L} \mathrm{~cm}^{-1}$ ), $\mathrm{L}$ is the optical length of the vial $(1.33 \mathrm{~cm})$ and $\mathrm{m}$ is the mass of immobilized laccase in $\mathrm{g}$.

Effect of temperature and $\mathrm{pH}$ on the activity of immobilized laccase

The $\mathrm{pH}$ effect on the activity of the immobilized laccase was determined in the $\mathrm{pH}$ range 2-10. Results were expressed as relative activity, i.e., the activity normalized to the maximum activity observed.

Temperature effect on enzyme activity of the selected carrier was studied in the range $10-60{ }^{\circ} \mathrm{C}$. A mass of immobilized laccase equivalent to $0.08 \mathrm{U}, 0.2 \mathrm{~cm}^{3}$ of $20 \mathrm{mmol} \mathrm{L}^{-1}$ ABTS and $3.8 \mathrm{~cm}^{3}$ of $\mathrm{pH} 5.0$ citrate-phosphate buffer, acclimated to the test temperature, were transferred to $10 \mathrm{~cm}^{3}$ screw-capped vials. The same protocol was used for free laccase. The vials with free and immobilized laccase were shaken in a bench shaker at $150 \mathrm{rpm}$ for $10 \mathrm{~min}$. Results were presented as relative activity.

\section{Reuse of immobilized laccase}

Activity of the first reaction cycle was determined using $2 \mathrm{mg}$ of immobilized laccase. After that, $(i)$ the vial was centrifuged, (ii) the supernatant was removed, (iii) deionized water was added, ( $i v)$ the vial was centrifuged again and then $(v)$ the washing water was withdrawn. Steps (iii) to $(v)$ were repeated until the concentration of oxidized ABTS was lower than the detection limit by spectrophotometry at $420 \mathrm{~nm}$. The washed immobilized laccase was used to determine the activity of the second reaction cycle. The immobilized laccase was reused until the eighth reaction cycle. The swelling effect on the activity recovery over subsequent reaction cycles was evaluated by using the same amount of immobilized laccase, previously hydrated in deionized water at room temperature for $24 \mathrm{~h}$.

Removal of BPA from aqueous solution by free and immobilized laccase: effect of $\mathrm{pH}$ and temperature

The $\mathrm{pH}$ effect on BPA removal by free and immobilized laccase was evaluated over the $\mathrm{pH}$ range 2-10. Aliquots of $4 \mathrm{~cm}^{3}$ of $10 \mathrm{mg} \mathrm{L}^{-1} \mathrm{BPA}$ in buffer solution at the test $\mathrm{pH}$ and laccase were transferred to $10 \mathrm{~cm}^{3}$ vials, which were shaken at $150 \mathrm{rpm}$ and $25^{\circ} \mathrm{C}$ for $2 \mathrm{~h}$. Experiments using free laccase were carried out with an enzyme concentration of $10 \mathrm{U} \mathrm{cm}^{-3}$, while those with the immobilized laccase used a concentration of $0.13 \mathrm{U} \mathrm{cm}^{-3}$. In order to stop the reaction, it was added $1 \mathrm{mM}$ sodium azide (an irreversible inhibitor of laccase) to the reaction mixture. Samples were maintained at $-20^{\circ} \mathrm{C}$ until analyzed by HPLC-UV (high-performance liquid chromatography with ultraviolet detector).

Temperature effect was studied within the range 10-60 ${ }^{\circ} \mathrm{C}$, using the same protocol except $\mathrm{pH}$, which was fixed at 7.0, and laccase concentration, which was $0.4 \mathrm{U} \mathrm{cm}^{-3}$ for the free and immobilized form.

Residual BPA was determined by isocratic elution with $60 \% \mathrm{ACN}: \mathrm{H}_{2} \mathrm{O}$ at $1 \mathrm{~cm}^{3} \mathrm{~min}^{-1}$, in an Agilent 1260 Infinity LC system (USA) fitted with a C18 column (Lichrospher 100 RP-18, 5 m , Merck Millipore, Brazil), maintained at $30{ }^{\circ} \mathrm{C}$. The analyte was detected at $277 \mathrm{~nm}$.

\section{Determination of BPA adsorption on the immobilized laccase}

To evaluate the BPA adsorption and enzymatic conversion by the immobilized laccase, experiments were carried with ( $i$ ) the immobilized laccase, (ii) PDA-modified resin, (iii) immobilized enzyme inactivated by azide and (iv) free laccase inactivated by azide. The experiment with inactivated free laccase was used to check the efficiency of the inactivation by azide and to determine any adsorption onto the enzyme.

BPA solutions $\left(10 \mathrm{mg} \mathrm{L}^{-1}\right)$ were prepared in $\mathrm{pH} 7.0$ citrate-phosphate and $\mathrm{pH} 10$ carbonate buffer. The same enzyme concentration $\left(0.4 \mathrm{U} \mathrm{cm}^{-3}\right)$ was used in experiments using free and immobilized laccase. Laccase (free or immobilized), $1 \mathrm{mmol} \mathrm{L}-1$ sodium azide (for experiments with inactive enzyme) and then $3 \mathrm{~cm}^{3}$ of BPA solution were added to $10 \mathrm{~cm}^{3}$ screw capped vials. The vials were then 
stirred at $150 \mathrm{rpm}$ and $25^{\circ} \mathrm{C}$ for $2 \mathrm{~h}$ and then sodium azide in the vials with active immobilized laccase was added. In the experiments with PDA-modified resin, $30 \mathrm{mg}$ of resin was used instead of immobilized laccase. In the presence of $1 \mathrm{mmol} \mathrm{L}^{-1}$ sodium azide, the activity of immobilized laccase was not detected.

\section{Results and Discussion}

\section{Characterization of poly(GMA-co-EGDMA)}

${ }^{13} \mathrm{C}$ NMR spectrum (Figure 2A) shows resonance peaks at $18.87 \mathrm{ppm}$ for methyl carbon, $45.82 \mathrm{ppm}$ for $\mathrm{C} 2$ epoxide carbon and quaternary carbon, $49.59 \mathrm{ppm}$ for $\mathrm{C} 3$ epoxide carbon, $55.72 \mathrm{ppm}$ for secondary carbon bonded to carbon, $67.62 \mathrm{ppm}$ for secondary carbon bonded to ester and $177.93 \mathrm{ppm}$ for ester carbonyl carbon. The presence of quaternary carbon demonstrates the formation of the polymer chain while the absence of a resonance peak of $\mathrm{C}=\mathrm{C}$ carbon suggests the high crosslinking of the copolymer.

A
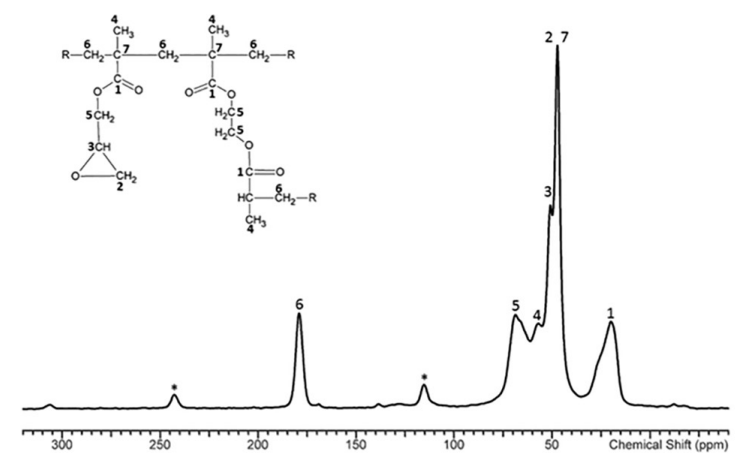

B

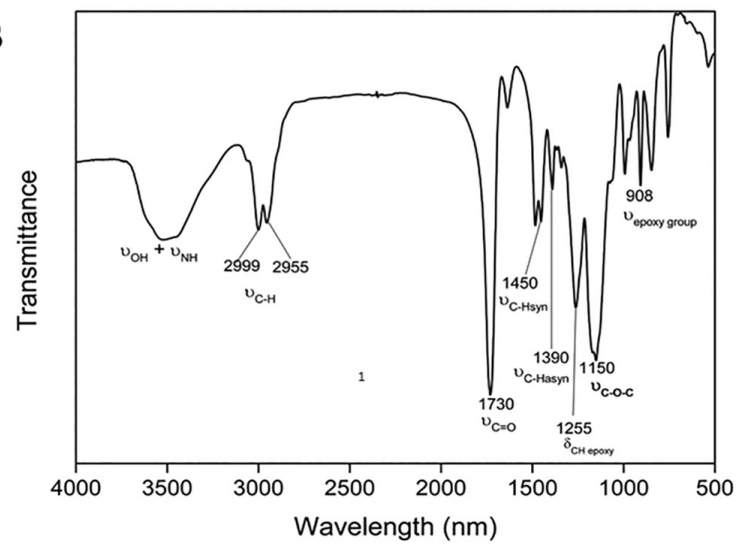

Figure 2. (A) ${ }^{13} \mathrm{C}$ NMR and (B) FTIR spectra of the GMA-co-EGDMA of the non-modified.

The chemical structure of the copolymer was confirmed by FTIR and solid-state NMR spectroscopy. The main absorption bands in the FTIR spectra of the GMA-co-EGDMA (Figure 2B) are (i) 2999 and
$2955 \mathrm{~cm}^{-1}\left(\mathrm{v}_{\mathrm{C}-\mathrm{H}}\right)$, (ii) $1730 \mathrm{~cm}^{-1}\left(\mathrm{v}_{\mathrm{C}=\mathrm{O}}\right)$, (iii) 1390 and $1450 \mathrm{~cm}^{-1}\left(\delta_{\mathrm{C}-\mathrm{Hasym}}\right.$ and $\left.\delta_{\mathrm{C}-\mathrm{Hsym}}\right)$, and $(i v) 1150 \mathrm{~cm}^{-1}\left(\mathrm{v}_{\mathrm{C}-\mathrm{O}-\mathrm{C}}\right)$. In addition, the epoxy peaks found in the spectrum of the initial copolymers are at $(v) 850$ and $910 \mathrm{~cm}^{-1}$ (epoxy ring vibrations) and $1255 \mathrm{~cm}^{-1}\left(\delta_{\mathrm{C}-\mathrm{H} \text { epoxy }}\right)$. The presence of epoxy in the copolymer structure is fundamental, since that group will be chemically modified in the synthesis of enzyme carrier.

Laccase immobilization on carriers with different functional groups

Selection of a suitable carrier is essential for the success of enzyme immobilization. With that purpose, the resin GMA-co-EGDMA was reacted with diamines EDA and PDA, diazotized and used as carrier. PDA modification was carried out in DMF medium and $\mathrm{pH} 9.0$ carbonate buffer ${ }^{14}$ and the immobilization capacity was compared. Unmodified (GMA-EGDMA) and aminated and glutaraldehyde-activated (AMINO-GLUT) resins were also used as carriers.

Except for the carrier PDA-DMF, the ability of the carriers to immobilize laccase dissolved in buffer was roughly similar $\left(3-9 \times 10^{3} \mathrm{U} \mathrm{g}^{-1}\right.$ carrier, Table 1).

However, after washing the microspheres to remove the unbound laccase, the remaining activity on the catalytic carrier was in the range of $0.36-96.3 \mathrm{U} \mathrm{g}^{-1}$ carrier.

Enzyme activity is expected to depend on the reaction between the reactive groups on the carrier and specific AA residues of the enzyme surface. The immobilization of laccase onto the unmodified resin GMA-co-EGDMA is based on the possibility of reaction, at neutral $\mathrm{pH}$, between its epoxy and the amino and thiol groups on the enzyme surface, forming strong covalent bonds via opening of the epoxy ring. ${ }^{6}$ Besides the amount of immobilized laccase on the GMA-EGDMA carrier was significant $\left(6.87 \times 10^{3} \mathrm{U} \mathrm{g}^{-1}\right.$ carrier); the activity of the immobilized laccase was only $0.36 \mathrm{U} \mathrm{g}^{-1}$ carrier. This low activity was probably due to the low rate of the reaction between epoxy groups and/or changes of the 3D structure of the active site when attaching onto the carrier.

The modification of the resin by amination followed by glutaraldehyde activation formed a carrier (AMINO-GLUT) with improved laccase immobilization activity. Covalent attachments are formed via nucleophilic attack, by reaction between aldehyde groups of the carrier and amino groups mostly from residues of lysine on the laccase surface. ${ }^{6}$ In addition, the activity of immobilized enzyme on the carrier was increased (19.6 $\mathrm{U} \mathrm{g}^{-1}$ carrier), which can be explained by $(i)$ the high reactivity of the aldehyde group with amino groups and (ii) the fact that glutaraldehyde acts as a space 
Table 1. Immobilized activity and activity of the resulting immobilized laccase after incubation of free laccase with chemically different carriers

\begin{tabular}{lcccc}
\hline Carrier & Functional group & $\begin{array}{c}\text { Starting activity / } \\
\left(\mathrm{U} \mathrm{g}^{-1} \text { carrier }\right)\end{array}$ & $\begin{array}{c}\text { Immobilized laccase } / \\
\left(\mathrm{U} \mathrm{g} \mathrm{g}^{-1} \text { carrier }\right)\end{array}$ & $\begin{array}{c}\text { Activity on the carrier } \\
\left(\mathrm{U} \mathrm{g}^{-1} \text { carrier }^{\mathrm{b}}\right)\end{array}$ \\
\hline GMA-EGDMA & epoxy & $(35.9 \pm 0.7) \times 10^{3}$ & $(6.87 \pm 0.41) \times 10^{3}$ & $0.36 \pm 0.04$ \\
AMINO-GLUT & aldehyde & $(37.7 \pm 1.5) \times 10^{3}$ & $(9.93 \pm 0.79) \times 10^{3}$ & $19.6 \pm 1.6$ \\
PDA-DMF-DIAZO & phenyldiazonium & $(14.6 \pm 0.4) \times 10^{3}$ & $(5.17 \pm 0.49) \times 10^{3}$ & $96.3 \pm 3.9$ \\
PDA-BUF-DIAZO & phenyldiazonium & $(13.8 \pm 0.5) \times 10^{3}$ & $(3.05 \pm 0.16) \times 10^{3}$ & $20.6 \pm 1.5$ \\
EDA-DMF-DIAZO & ethyldiazonium & $(6.27 \pm 0.3) \times 10^{3}$ & $(2.97 \pm 0.24) \times 10^{3}$ & $1.35 \pm 0.10$ \\
PDA-DMF & amino & $(34.0 \pm 0.9) \times 10^{3}$ & $(0.7 \pm 0.10) \times 10^{3}$ & $0.80 \pm 0.08$ \\
\hline
\end{tabular}

a Starting activity is the activity $(\mathrm{U})$ of the laccase solution in the beginning of the immobilization per mass of carrier $(\mathrm{g})$; bimmobilized laccase is equal to the starting activity less the activity at the end of the immobilization; 'activity on the carrier is the activity of the laccase immobilized on the carrier after removing the unbounded enzyme. GMA-EGDMA: glycidyl methacrylate-ethyleneglycol dimethacrylate; AMINO-GLUT: resin modified by $\mathrm{NH}_{4} \mathrm{OH}$ aqueous solution followed by glutaraldehyde activation; PDA-DMF-DIAZO: resin modified by $p$-phenylenediamine in DMF and then diazoted; PDA-BUF-DIAZO: resin modified by $p$-phenylenediamine in buffer and then diazoted; PDA-DMF: resin modified by $p$-phenylenediamine in dimethylformamide; EDA-DMF-DIAZO: resin modified by ethylenediamine in DMF and then diazoted.

arm between the resin and the enzyme, which provides higher accessibility of the active site to the substrate. ${ }^{19}$

Two strategies were tested to introduce the PDA diamine into the GMA-EDGMA resin: the reaction in the presence of DMF (method M-1) and the reaction in aqueous medium (at $\mathrm{pH}$ 9.0) (method M-2).

Figure $3 \mathrm{~A}$ shows some evidence of chemical modification of the PDA-DMF resin: (i) the reduction of the symmetrical and asymmetrical ring stretching of the

A

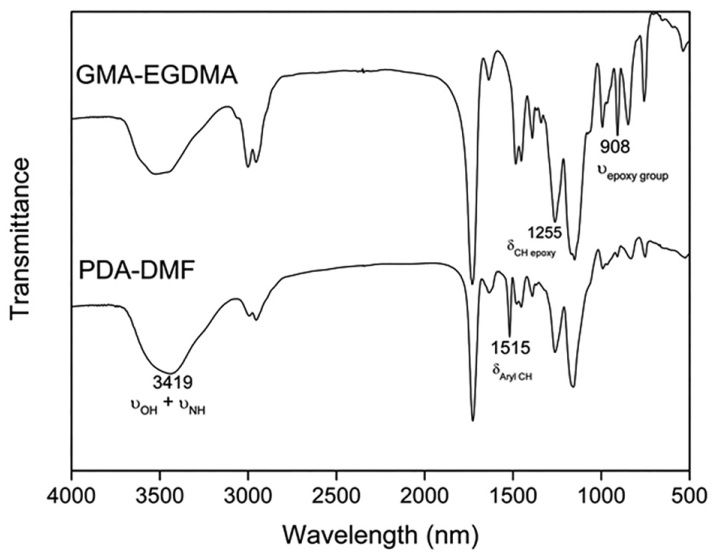

B

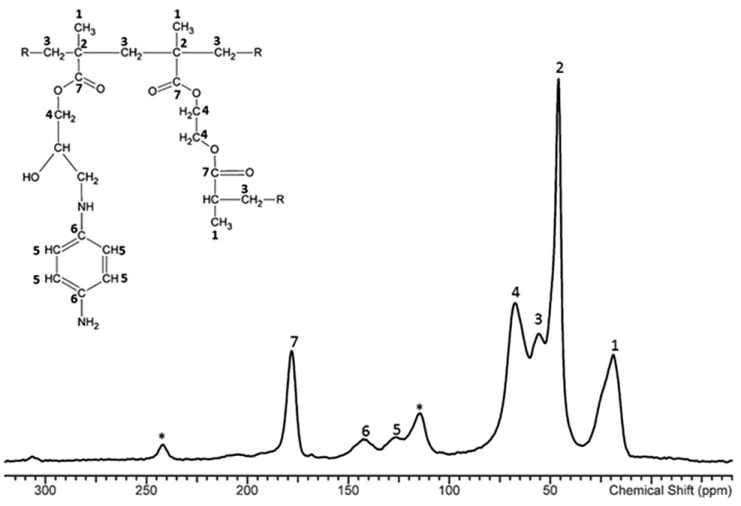

Figure 3. (A) FTIR and (B) ${ }^{13} \mathrm{C}$ NMR spectra of the GMA-co-EGDMA modified by PDA. epoxide ring at 1250 and $908 \mathrm{~cm}^{-1}$, (ii) the broadening of the band at $3419 \mathrm{~cm}^{-1}$, representative of $\mathrm{N}-\mathrm{H}$ stretching vibration in primary amines and $\mathrm{O}-\mathrm{H}$ stretching in alcohols, and (iii) the appearance of a band at $1515 \mathrm{~cm}^{-1}$ due to the $\mathrm{N}-\mathrm{H}$ bending vibrations of secondary aromatic amines. ${ }^{20} \mathrm{In}$ addition, ${ }^{13} \mathrm{C}$ NMR spectrum (Figure $3 \mathrm{~B}$ ) showed resonance peaks at 126.63 and $142.78 \mathrm{ppm}$ for unsubstituted aromatic carbon and amino-substituted aromatic carbon, respectively. No peak was detected in chemical shift range for epoxy group.

Those changes can be explained by the opening of the epoxy ring through nucleophilic attack of the unprotonated amino group of PDA on the carbon of the epoxy group, forming $\mathrm{C}-\mathrm{N}$ bond between the resin and diamine.

PDA is more likely to react with the epoxy groups of the resin using DMF (method M-1) than carbonate buffer as solvent (method M-2). Water is a polar protic solvent that interacts with PDA via hydrogen bonds, forming a shell of water molecules. That makes PDA a nucleophile that is less reactive in water than in DMF, which is a polar aprotic solvent and so does not form hydrogen bonds. ${ }^{21}$ Consequently, the carrier synthesized in aqueous medium (method M-2) will have few diazonium salts to form covalent attachments with the enzyme, resulting in a carrier with an inferior catalytic activity (20.6 $\mathrm{U} \mathrm{g}^{-1}$ carrier).

The PDA-DMF resin was also used as a carrier, since its amino groups can react with AA with a carboxylic group, forming a stable amide bond. That seems to be quite possible for T. versicolor laccase, since $17 \%$ of the amino acid sequence is composed of glutamate and aspartate. ${ }^{22}$ Nevertheless, the amount of immobilized laccase $\left(0.7 \times 10^{3} \mathrm{U} \mathrm{g}^{-1}\right.$ carrier $)$ on PDA-DMF was considerably lower than the activity of other carriers.

Diazonium salts $\left(\mathrm{R}-\mathrm{N} \equiv \mathrm{N}^{+}\right)$are good electrophiles for activated aromatic rings, such as the groups phenol 
(tyrosine), imidazole ( $L$-histidine) and others of the enzyme laccase group. ${ }^{8}$ Through nucleophilic substitution, a diazo bond can be formed in the meta position of PDA. However, if $\mathrm{R}$ is an alkyl group, the diazonium salt formed is quite unstable and is immediately converted into an alcohol in aqueous medium. ${ }^{21}$ When $\mathrm{R}$ is an aryl group, the diazonium salt is stable and can react with a nucleophile such as phenol.

Although the amount of EDA in the resin modified in DMF (2.6 mmol g $\left.\mathrm{g}^{-1}\right)$ was high, diazotization of that resin gave an unstable diazonium salt, which reacted readily with water, yielding an alcohol and nitrogen gas. As a result, the immobilization of laccase on the carrier EDA-DMF-DIAZO showed activity of $1.35 \mathrm{U} \mathrm{g}^{-1}$ carrier, which was much lower than the activity on the carrier PDA-DMF-DIAZO.

Laccase immobilized on PDA-DMF-DIAZO showed the highest activity among the tested carriers, so it was used to evaluate (i) the effect of $\mathrm{pH}$ and temperature, (ii) the capacity for reuse, and (iii) the capacity for conversion of BPA.

$\mathrm{pH}$ and temperature effect on enzyme activity and BPA removal

As shown in the Figure 4A, the pH curve for BPA conversion by free laccase was bell shaped, with optimum $\mathrm{pH}$ range of 5.0-7.5. Most phenolic substrates with alkaline $\mathrm{pKa}$ have a $\mathrm{pH}$ profile from 2.7 to 10 with optimum $\mathrm{pH}$ of 5.0. ${ }^{23}$ The main reason why the maximum conversion occurred in a broad $\mathrm{pH}$ range is that an excessive amount of enzyme was used, reaching complete conversion at various $\mathrm{pH}$ values. ${ }^{24}$ In the presence of immobilized enzyme, BPA was removed in a similar $\mathrm{pH}$ range (3.0-10.5) and the optimum $\mathrm{pH}$ was observed at 7.0.

Temperature effect was moderately significant on BPA removal by free laccase, reaching maximum removal at $45^{\circ} \mathrm{C}$ and decreasing above that optimum (Figure 4B). However, it has been reported that when the reaction medium $\mathrm{pH}$ is adjusted to the optimum for BPA conversion, the temperature effect is more pronounced. ${ }^{25}$ With regard to the immobilized laccase, BPA removal decreased when increasing temperature in the range $10-50{ }^{\circ} \mathrm{C}$ and then the removal increased from 50 to $60{ }^{\circ} \mathrm{C}$. It can be supposed that other mechanisms than enzymatic conversion could be involved in BPA removal by immobilized laccase.

\section{Reuse of the immobilized laccase}

Leaking of enzyme in use can reduce the activity of immobilized enzyme, ${ }^{17}$ so this should be evaluated when developing a new immobilization method. Figure 5 shows that the non-swollen immobilized laccase kept $71 \%$ of the starting activity while the $24 \mathrm{~h}$ swollen showed
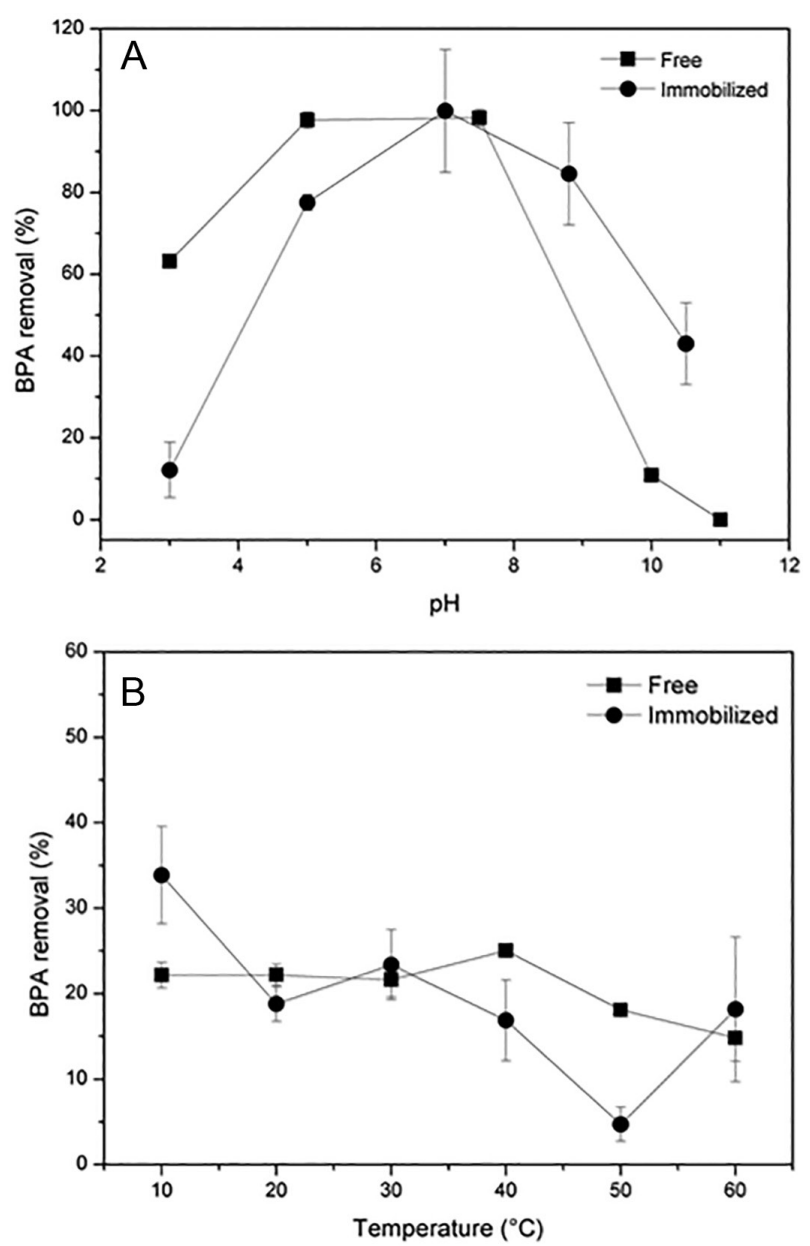

Figure 4. Effect of (A) $\mathrm{pH}$ and (B) temperature on BPA removal by free and immobilized laccase on PDA-DMF-DIAZO carrier. BPA removals in the $\mathrm{pH}$ evaluation were normalized to the maximum removal, which was $98 \%$ for free laccase and $45 \%$ for immobilized laccase.

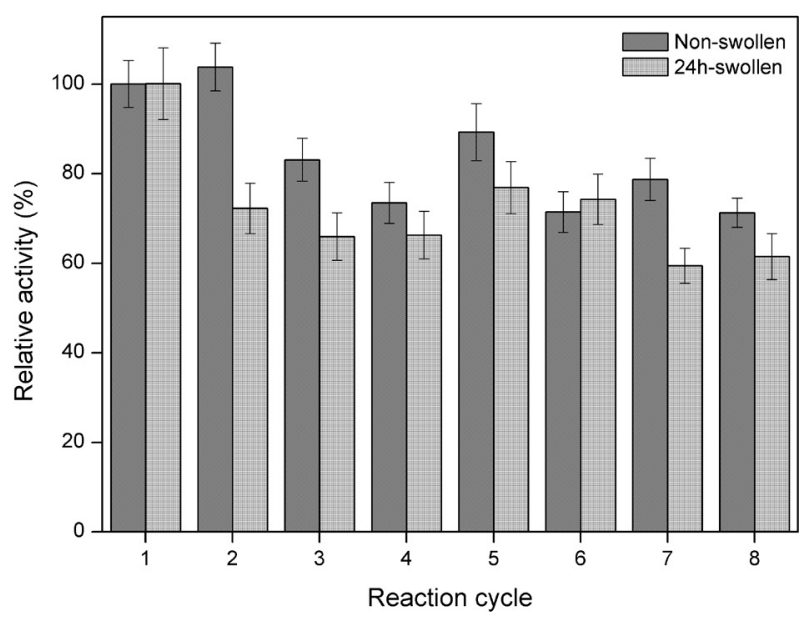

Figure 5. Relative activity of laccase immobilized on PDA-DMF-DIAZO carrier over eight cycles of ABTS oxidation. Reaction conditions: $2 \mathrm{mmol} \mathrm{L}{ }^{-1} \mathrm{ABTS}$, pH 5.0, reaction time of $10 \mathrm{~min}, 25^{\circ} \mathrm{C}$. 
$61 \%$ activity after eight cycles. Laccase immobilized on epoxy-acrylic supports (Eupergit beads) retained $73 \%$ of the starting activity after 8 cycles of $5 \mathrm{~h},{ }^{12}$ while laccase immobilized on a copolymer of butyl acrylate and ethylene glycol dimethacrylate treated by EDA and activated with glutaraldehyde retained only $4.1 \% .{ }^{26}$

Furthermore, we found that the initial activity of the swollen $\left(17.3 \mathrm{U} \mathrm{g} \mathrm{g}^{-1}\right)$ and non-swollen catalytic carrier $\left(18.6 \mathrm{U} \mathrm{g}^{-1}\right)$ were not significantly different. Hence, the previous swelling for $24 \mathrm{~h}$ does not affect the activity of the immobilized laccase. The resin GMA-co-EGDMA used for the preparation of the carrier is highly crosslinked with limited swelling in solvents such as water, DMF and methanol. Since the diameter of the pores does not increase when the carrier is hydrated, the diffusion rate of ABTS across the pores should be similar for both non-swollen and swollen immobilized laccase.

\section{Evaluation of BPA adsorption on the catalytic carrier}

Besides the laccase-catalyzed conversion, BPA can also be removed by adsorption on the carrier PDA-DMF-DIAZO used for laccase immobilization. Figure 6 shows the BPA removal by (i) active immobilized laccase, (ii) the resin PDA-DMF, (iii) inactivated immobilized laccase, and (iv) inactive free laccase. Since the molecular interactions between BPA and the carrier depend on the number of ionized molecules, the experiments described above were conducted at $\mathrm{pH} 7$, where most of the BPA molecules are neutral, and at $\mathrm{pH} 10$, where nearly $62 \%$ of the molecules are unprotonated.

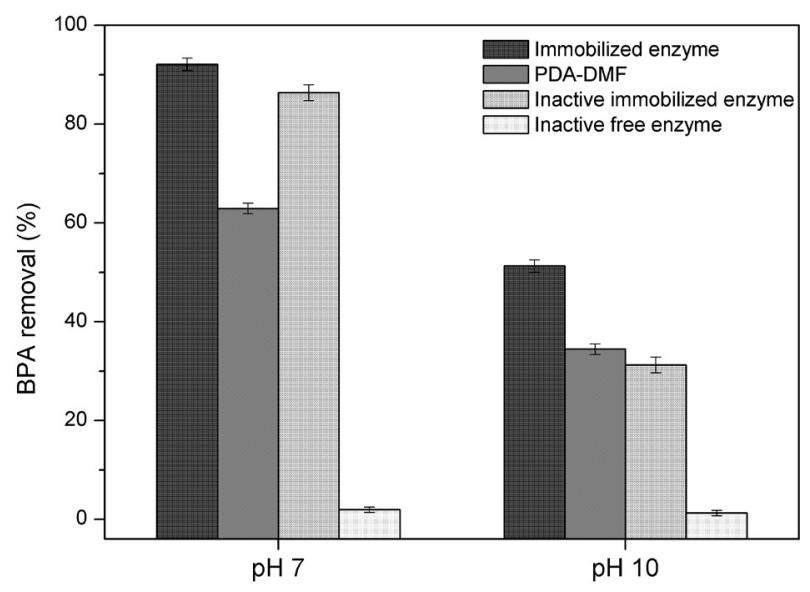

Figure 6. Comparison between the BPA removal by (i) active and (ii) inactivated immobilized enzyme, (iii) PDA-modified resin and (iv) inactive free enzyme. Experiments were carried out at $\mathrm{pH} 7$ and 10, at $25^{\circ} \mathrm{C}$.

It can be observed that there was no BPA removal by inactive free laccase at $\mathrm{pH}$ values 7 and 10 , which demonstrates that adsorption of BPA on AA residues of laccase is unlikely to happen. Azide forms stable complexes with copper atoms from the active site ${ }^{27}$ inhibiting the electron transfer from the substrate to molecular oxygen. Since the 3D structure of laccase is preserved after azide inactivation, the molecular interactions between inactive or active laccase are very similar.

From experiments at pH 7 (Figure 6), it can be observed that the BPA removal by active immobilized laccase $(93 \%)$ was slightly higher than that by the inactive form $(86 \%)$. Thus, adsorption on the carrier accounts for $92 \%$ of the BPA removed while enzymatic conversion accounts for $8 \%$. A significant fraction of BPA was adsorbed on PDA-modified resin (PDA-DMF), which can occur via molecular interactions, such as hydrogen bonding, $\pi-\pi$ interaction and hydrophobic interaction. Hydrogen bonds can be formed from interactions between the hydroxyl group of BPA and hydrogen receptor groups in the network of the resin, such as ketone, ether and hydroxyl. Adsorption can be also explained by $\pi-\pi$ interaction between the phenolic ring and the aromatic ring of the residue of PDA bonded to the resin. When the medium $\mathrm{pH}$ is 7, the electron-withdrawing group $\left(-\mathrm{NH}_{3}{ }^{+}\right)$ of the PDA and the electron-donating group $(-\mathrm{OH})$ of the BPA strengthen the $\pi-\pi$ interactions, where PDA acts as $\pi$-acceptor and BPA as $\pi$-donor. ${ }^{28}$ Hydrophobic interactions between the non-polar methyl groups of the BPA and the hydrocarbon skeleton of the copolymer can also contribute to adsorption, although those interactions involve weak forces. ${ }^{29}$ Considering that we used an aqueous medium, where the polar BPA is partially soluble, $\pi-\pi$ interactions were probably the main driving force of the sorption of BPA on the PDA-modified resin. ${ }^{8}$

The difference observed between the BPA removal by inactivated immobilized laccase $(86 \%)$ and that by PDA-modified resin (63\%), at $\mathrm{pH} 7$, is presumably due to the presence of residual phenyldiazonium groups in the PDA-DMF-DIAZO carrier. BPA can react with those electrophiles via nucleophilic attack, which can be considered a more efficient removal mechanism than adsorption.

When increasing the medium $\mathrm{pH}$ to 10 , the fraction of BPA removed by enzymatic conversion was considerably improved (33\%), but the laccase activity on BPA was lower at $\mathrm{pH} 10$, as previously shown in Figure 1.

BPA is an acid compound that exists predominantly in the ionized form when the medium $\mathrm{pH}$ is above of its pKa (9.78). Consequently, the octanol-water distribution coefficient (log Dow) is reduced from 3.64 to 2.87, increasing the water solubility and the hydrophilicity and decreasing the adsorption of BPA. ${ }^{29,30}$ As shown in 
Figure 6, when the medium $\mathrm{pH}$ was increased from 7 to 10 , adsorption of BPA on the carrier decreased from 86 to $31 \%$. According to Jung et al., ${ }^{30}$ adsorption of BPA on an activated biochar (moderately hydrophilic, with aromatic content of 74\%) dropped sharply at $\mathrm{pH}$ above its $\mathrm{pKa}$.

We found that the removal by inactivated immobilized laccase and PDA-modified resin was similar at $\mathrm{pH} 10$. The remaining diazonium salts in the carrier, which did not react with laccase during the immobilization, are readily converted to phenyldiazoate ( $\mathrm{Ar}-\mathrm{N}=\mathrm{N}-\mathrm{O}-$ ) salts at alkaline $\mathrm{pH}$. Unlike diazonium, diazote salts do not react with the phenolic ring of BPA. ${ }^{31}$

Adsorption could be a concern regarding the use of laccase supported on polymeric carriers, but it should be considered that the carrier has a finite number of adsorption sites. For BPA solutions with a low BPA/adsorption site molar ratio, it is likely that most of the BPA is removed by adsorption, since the number of adsorption sites in the porous resin is much higher than the number of active sites of laccase. However, when working with high concentration of BPA, some of its molecules are adsorbed after the carrier becomes saturated. Consequently, the chance of interaction between the molecules of BPA in solution and the active site of the enzyme increases, so enzymatic catalysis can be an important mechanism for removal.

To the best of our knowledge, this is the first report that adsorption and enzymatic conversion are the main mechanisms by which laccase immobilized on an acrylic resin removes BPA from aqueous media.

\section{Conclusions}

The copolymer GMA-co-EGDMA was chemically modified by different methods, giving six carriers for laccase immobilization. The capacity of the carriers to bind the enzyme was roughly similar, but the highest activity was observed for laccase immobilized on the carrier PDA-DMF-DIAZO. Inferior activity was obtained when the resin was modified by PDA in carbonate buffer, since the rate of the reaction between the diamine in aqueous medium is significantly lower.

Studies of the reusability of the selected immobilized laccase demonstrated that enzyme leaking is very low and that previous swelling of the catalytic carrier does not increase its activity. Moreover, the use of a polymeric carrier gives mechanical stability to the enzyme. Consequently, that method of laccase immobilization can be recommended for industrial applications, where stability to drastic conditions of $\mathrm{pH}$, temperature and shearing forces are required and the reuse of enzyme is necessary for the economic feasibility of the process.
Adsorption could be a concern regarding the use of laccase supported on polymeric carriers, since a fraction of the substrate can be adsorbed instead of enzymatically converted. However, the carrier has a finite number of adsorption sites, so when recycling the immobilized laccase, the carrier will be saturated at some point. Then the laccase-catalyzed conversion becomes the predominant BPA removal mechanism.

An important advantage of the carrier PDA-DMF-DIAZO is that the phenoxy radicals from the enzymatic oxidation of phenolic compounds can react with PDA and/or phenyldiazonium groups on the carrier. That reaction can minimize the presence of dimmers, trimmers and/or oligomers of phenolic compounds in the treated solution. While those by-products have low bioavailability, their effects in aquatic environment are still unknown.

\section{Acknowledgments}

We thank the Brazilian agencies CAPES, CNPq and FAPERJ for their financial support and Eduardo C. B. Guimarães, Maria L. D. Ferreira, Maria E. Arcanjo, Rita M. P. Sá and Rodrigo França for their technical assistance.

\section{References}

1. Mateo, C.; Palomo, J. M.; Fernandez-Lorente, G.; Guisan, J. M.; Fernandez-Lafuente, R.; Enzyme Microb. Technol. 2007, 40, 1451.

2. Sheldon, R. A.; Appl. Microbiol. Biotechnol. 2011, 92, 467.

3. Zhou, Z.; Hartmann, M.; Chem. Soc. Rev. 2013, 42, 3894.

4. Sheldon, R. A.; van Pelt, S.; Chem. Soc. Rev. 2013, 42, 6223.

5. Fernández-Fernández, M.; Sanromán, M. Á.; Moldes, D.; Biotechnol. Adv. 2013, 31, 1808.

6. Cantone, S.; Ferrario, V.; Corici, L.; Ebert, C.; Fattor, D.; Spizzo, P.; Gardossi, L.; Chem. Soc. Rev. 2013, 42, 6262.

7. Hanefeld, U.; Gardossi, L.; Magner, E.; Chem. Soc. Rev. 2009, 38,453 .

8. Li, X.; Wang, X.; Ye, G.; Xia, W.; Wang, X.; Polymer (Guildf). 2010, 51,860 .

9. Nelson, D.; Cox, M.; Lehninger Principles of Biochemistry; W. H. Freeman: New York, 2008.

10. Rodríguez Couto, S.; Toca Herrera, J. L.; Biotechnol. Adv. 2006, 24,500 .

11. Liu, Y.; Zeng, Z.; Zeng, G.; Tang, L.; Pang, Y.; Li, Z.; Liu, C.; Lei, X.; Wu, M.; Ren, P.; Liu, Z.; Chen, M.; Xie, G.; Bioresour. Technol. 2012, 115, 21.

12. Lloret, L.; Hollmann, F.; Eibes, G.; Feijoo, G.; Moreira, M. T.; Lema, J. M.; Biodegradation 2012, 23, 373.

13. Donia, A. M.; Atia, A. A.; El-Boraey, H. A.; Mabrouk, D. H.; Sep. Purif. Technol. 2006, 48, 281. 
14. Diano, N.; Grano, V.; Fraconte, L.; Caputo, P.; Ricupito, A.; Attanasio, A.; Bianco, M.; Bencivenga, U.; Rossi, S.; Manco, I.; Mita, L.; Del Pozzo, G.; Mita, D. G.; Appl. Catal., B 2007, 69, 252.

15. Miletić, N.; Rohandi, R.; Vuković, Z.; Nastasović, A.; Loos, K.; React. Funct. Polym. 2009, 69, 68.

16. Costa, L. C.; Gomes, A. S.; Coutinho, F. M. B.; Teixeira, V. G.; React. Funct. Polym. 2010, 70, 738.

17. Miletić, N.; Nastasović, A.; Loos, K.; Bioresour. Technol. 2012 , $115,126$.

18. Fukuda, T.; Uchida, H.; Takashima, Y.; Uwajima, T.; Kawabata, T.; Suzuki, M.; Biochem. Biophys. Res. Commun. 2001, 284, 704.

19. Bai, Y.-X.; Li, Y.-F.; Yang, Y.; Yi, L.-X.; Process Biochem. 2006, 41,770 .

20. Silverstein, R. M.; Bassler, G. C.; Morril, T. C.; Identificação Espectrométrica de Compostos Orgânicos, $5^{\mathrm{a}}$ ed.; John Wiley \& Sons, Inc: Rio de Janeiro, 1994.

21. Clayden, J.; Greves, N.; Warren, S.; Wothers, P.; Organic Chemistry, $1^{\text {st }}$ ed.; Oxford University Press: New York, 2001.
22. Minussi, R. C.; Miranda, M. A.; Silva, J. A.; Ferreira, C. V.; Aoyama, H.; Rotilio, D.; Pastore, G. M.; Durán, N.; Afr. J. Biotechnol. 2010, 6, 1248.

23. Xu, F.; J. Biol. Chem. 1997, 272, 924.

24. Modaressi, K.; Taylor, K. E.; Bewtra, J. K.; Biswas, N.; Water Res. 2005, 39, 4309.

25. Kim, Y.-J.; Nicell, J. A.; Bioresour. Technol. 2006, 97, 1431.

26. Bryjak, J.; Kruczkiewicz, P.; Rekuć, A.; Peczyńska-Czoch, W.; Biochem. Eng. J. 2007, 35, 325.

27. Johannes, C.; Majcherczyk, A.; J. Biotechnol. 2000, 78, 193.

28. Lin, D.; Xing, B.; Environ. Sci. Technol. 2008, 42, 7254.

29. Pan, B.; Xing, B.; Environ. Sci. Technol. 2008, 42, 9005.

30. Jung, C.; Park, J.; Lim, K. H.; Park, S.; Heo, J.; Her, N.; Oh, J.; Yun, S.; Yoon, Y.; J. Hazard. Mater. 2013, 263, 702.

31. Arora, A.; Organic Chemistry: Aromatic, Alcohols Aldehydes \& Acids; Discovery Publishing House: New Delhi, 2006.

Submitted: December 5, 2016

Published online: April 13, 2017 